\title{
Interactions of local habitat type, landscape composition and flower availability moderate wild bee communities
}

\author{
Ulrich Neumüller (D) Hannah Burger • Sabrina Krausch • Nico Blüthgen • \\ Manfred Ayasse
}

Received: 18 December 2019/Accepted: 14 August 2020/Published online: 25 August 2020

(C) The Author(s) 2020

\begin{abstract}
Context Landscape and local habitat traits moderate wild bee communities. However, whether landscape effects differ between local habitat types is largely unknown.

Objectives We explored the way that wild bee communities in three distinct habitats are shaped by landscape composition and the availability of flowering plants by evaluating divergences in response patterns between habitats.

Methods In a large-scale monitoring project across 20 research areas, wild bee data were collected on three habitats: near-natural grassland, established flower plantings and residual habitats (e.g. field margins). Additionally, landscape composition was mapped around the research areas.

Results Our monitoring produced a dataset of 27,650 bees belonging to 324 species. Bee communities on all three habitats reacted similarly to local flower
\end{abstract}

Electronic supplementary material The online version of this article (https://doi.org/10.1007/s10980-020-01096-4) contains supplementary material, which is available to authorized users.

U. Neumüller $(\bowtie) \cdot H$. Burger $\cdot$ S. Krausch $\cdot$ M. Ayasse Institute of Evolutionary Ecology and Conservation Genomics, Ulm University, 89081 Ulm, Germany

e-mail: ulrich.neumueller@uni-ulm.de

\section{N. Blüthgen}

Ecological Networks, Department of Biology, Technical University of Darmstadt, 64287 Darmstadt, Germany availability. Intensively managed grassland in the surrounding landscape had an overall negative effect on the studied habitats. Other landscape variables produced diverging response patterns that were particularly pronounced during early and late season. Bee communities in near-natural grassland showed a strong positive response to ruderal areas. Flower plantings and residual habitats such as field margins showed a pronounced positive response to extensively managed grassland and woodland edges. Response patterns regarding bee abundance were consistent with those found for species richness.

Conclusion We advise the consideration of local habitat type and seasonality when assessing the effect of landscape context on bee communities. A reduction in the intensity of grassland management enhances bee diversity in a broad range of habitats. Moreover, wild bee communities are promoted by habitat types such as ruderal areas or woodland edges.

Keywords Wild bee - Landscape composition . Grassland · Pollination $\cdot$ Flower planting

\section{Introduction}

Wild bees are key pollinators within natural ecosystems and croplands (Kearns et al. 1998; Kratochwil 2003; Bommarco et al. 2012; Holzschuh et al. 2012). Because evidence is accumulating for ongoing wild 
bee decline (Biesmeijer et al. 2006; Potts et al. 2010; Bystriakova et al. 2018), widespread ecological and economic interest is being shown in preserving pollination services in agroecosystems (Chopra et al. 2015; Melathopoulos et al. 2015). The conservation of semi-natural habitats (Banaszak 1992; Albrecht et al. 2007) and the establishment of novel habitats such as flower strips (Scheper et al. 2013, 2015; Blaauw and Isaacs 2014) have been shown to be successful for the promotion of wild bee communities and consequently for their pollination services.

The abundance and richness of bee communities are predominantly driven by two factors: local habitat conditions and the quality of the surrounding landscape (Kennedy et al. 2013). The quality of local habitat conditions for bees depends upon the availability of distinctive floral resources (flower cover, plant species) and suitable nesting sites (Zurbuchen and Müller 2012). In agroecosystems, these conditions are strongly affected by periodic disturbance events, mostly by anthropogenic management measures such as mowing, fertilizing, grazing and pesticide use. Disturbances not only have direct effects on bees (Fluri and Frick 2002; Goulson 2013), but also alter plant communities, which in turn have strong effects on species richness and the abundance of bees (Gathmann et al. 1994; Steffan-Dewenter and Tscharntke 2001; Potts et al. 2003). The bee habitats of existing agricultural landscapes, such as field margins, woodland or flower plantings, strongly differ in their local habitat conditions. Consequently, it is important to account for local habitat conditions, especially when comparing among habitat types.

In addition to local habitat conditions, landscape composition plays an essential role in shaping local bee communities (Kennedy et al. 2013). Individual bee species need suitable food plants, nesting places and nest building resources, which are often not provided by a single biotope (Westrich 1989). Thus, bee communities strongly depend on structurally rich landscapes that offer a variety of resources (Bommarco et al. 2010). As a result, intensively managed agricultural landscapes, which offer a poor selection of floral resources, are dominated by relatively common, generalist bees (Wood et al. 2017; Ahrenfeldt et al. 2019; Grab et al. 2019).

Bees are highly mobile and are able to move between different habitats within achievable flight distances (Potts et al. 2005; Neumüller et al. 2018). If the landscape is diverse, wild bees can switch between complementary habitat types to avoid temporary declines of feeding sources (Mandelik et al. 2012; Tscharntke et al. 2012). Moreover, bee communities quickly recover from severe disturbance events if, a stable meta community is present in the surrounding area (Potts et al. 2005; Neumüller et al. 2018). Seminatural habitats that host a high diversity of native flowering plants can act as an important buffer for disturbances and temporal fluctuations in floral resource availability (Mandelik et al. 2012; Tscharntke et al. 2012; Ogilvie and Forrest 2017). Accordingly, numerous studies have shown, that bee richness increases with a higher proportion of semi-natural habitats such as diverse grassland or hedges in a landscape (e.g. Le Féon et al. 2010; Kennedy et al. 2013; Hopfenmüller et al. 2014; Hass et al. 2018). However, commonly used term "semi-natural habitat" comprises a broad range of habitat types that can strongly differ with regard to local habitat conditions such as floral resource composition and availability.

For this large-scale study, we monitored wild bees in 20 regions across Germany and characterized the landscape context in the surroundings of the sampling plots. The sampling plots were established on three different habitat types: near-natural grassland, newly established flower plantings and residual habitats such as field margins and rarely used field paths. Subsequently, we examined how wild bee richness, abundance and composition in each of the three habitat types (near-natural grassland, flower plantings, residual habitats) was influenced by the composition of landcover types in the surrounding landscape. We also controlled for local habitat conditions by adding local floral availability into our models.

As manmade habitats, flower plantings may only provide suitable feeding resources to a subset of the regional bee community, depending on the floral resources available. Consequently, our first hypothesis was that bee communities on flower plantings would be more strongly moderated by local habitat characteristics than by the surrounding landscape structure.

Local habitat factors strongly affect the composition of wild bee communities (Westrich 2018). Hence, our second hypothesis was that bee communities on different habitat types may react differently to the surrounding landscape. Our third hypothesis was that landscape effects on wild bee communities may follow seasonal patterns, as resource availability in 
differing landscape elements shows complementary temporal distribution (Wray and Elle 2014; Mallinger et al. 2016).

Habitat edges can attract a distinct fauna that reflects different adjacent habitats, creating a zone of overlap that houses a greater overall species richness (Ewers and Didham 2006). But edge can also decrease faunal species richness and abundance if adjacent areas are subject to unfavourable human management (Kershner and Bollinger 1996; Fluri and Frick 2002; Battin 2004). Hence, our last hypothesis was that bees inhabiting habitat patches with a high edge-to surface ratio, such as field margins and paths (residual habitats) would be more affected by surrounding landscape composition and agricultural practices than communities in patches embedded in contiguous habitats such as near-natural grasslands.

To investigate these hypotheses, we analysed the response patterns for early, mid and late seasons of a year and tested whether the shape of a habitat type influenced the reaction of the inhabiting bee community to the surrounding landscape. This approach allowed us to demonstrate the effects of different sets of local and landscape factors on bee communities and to illustrate whether response patterns vary between local habitat types and seasons.

\section{Material and methods}

The present study is embedded in the BienABest project that aims to increase wild bee diversity and improve the ecosystem service of pollination in agricultural landscapes (www.bienabest.de). The project incorporates extensive wild bee monitoring on near-natural grassland, flower plantings and residual habitat elements, all of which have provided data concerning bee diversity and abundance for this study.

\section{Study region}

Data were collected on 180 plots within 20 landscapes composed of agricultural and semi-natural areas, distributed over seven federal states of Germany (Fig. 1). The selection of the areas was based mainly on the presence of near-natural grassland bodies embedded in an agricultural landscape matrix. The total extent of the study area was $708 \mathrm{~km}$

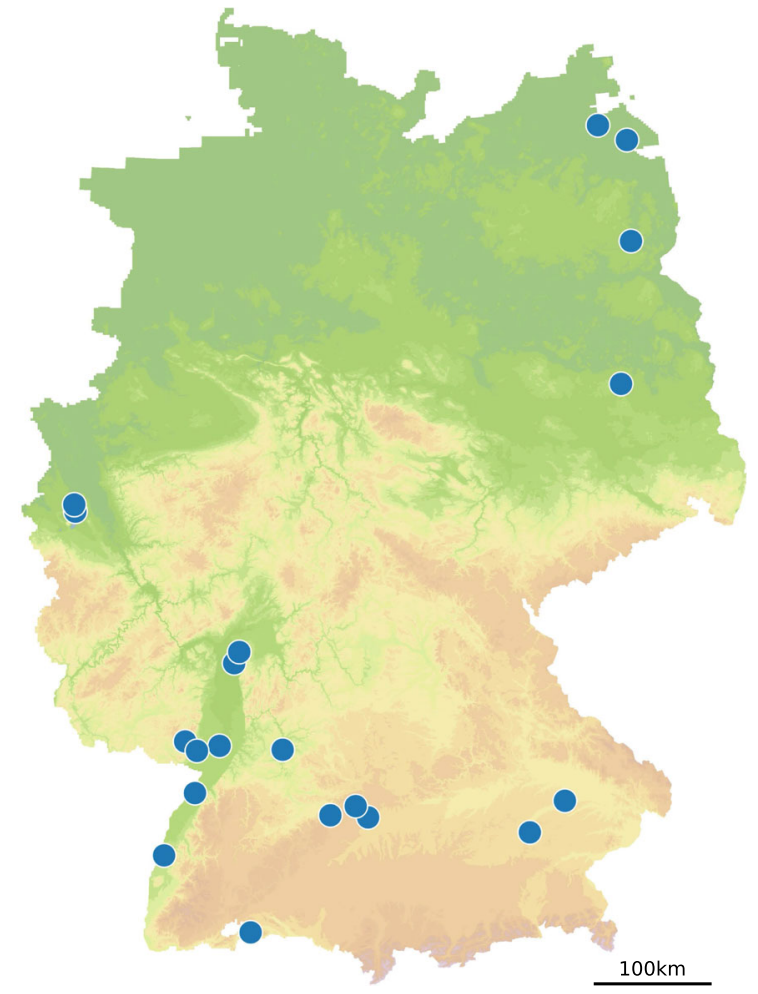

Fig. 1 Map of Germany showing the distribution of the 20 landscapes in which the study was performed. Each dot represents a landscape. Red areas represent a high topographical elevation; green areas represent a low topographical elevation (BKG 2013)

longitudinally and $507 \mathrm{~km}$ latitudinally, with altitude varying between 20 and $580 \mathrm{~m}$ above sea level.

Data collection took place on three different habitat types: near-natural grassland, flower plantings and residual habitats. Sampling plots were established during the course of the BienABest project. Within each of the 20 landscapes, we established three 0.3-ha sampling plots per habitat type (for exemplary maps of research areas see Supplementary Material Fig. S1), resulting in a total of 180 sampling plots. The same 0.3-ha plots were sampled during each of the five sampling rounds. Near-natural grassland was characterized by a high diversity of native flowering plants and extensive management, either by being mowed once or twice a year or by being grazed by sheep, goats or donkeys. The quality and character of near-natural grassland plots were known from previous wild bee surveys by wild bee experts involved in this study. Flower plantings were established on tilled arable land, during either the autumn or spring prior to the 
field surveys, and were sown with seed mixtures consisting of between 25 and 36 species encompassing regionally native and naturalized plant species with a complementary phenology to provide floral resources throughout the season. With regard to plant selection, bee-plant interaction data recorded in the 'Wildbienen Kataster Baden-Württemberg' (https://www. wildbienen-kataster.de) was evaluated and the most attractive plant species for bees were included in our seed mixtures. In addition to the plants in the seed mixture, the spontaneous growth of non-sown wild herbs was observed for all flower plantings (see Supplementary Material Table S1 for a detailed list of recorded plant species). Near-natural grassland and residual habitats were irregularly mown or grazed. In contrast, flower plantings were not mown until the last field survey was performed. Residual habitats were chosen to represent potential bee habitat areas still present in agricultural areas such as field margins, rarely used field paths and small patches of ruderal areas. Because of their usually elongated shape, the mean edge to surface area ratio over all 60 residual habitat plots $(0.222 \pm 0.103)$ was more than double that of all 60 flower plantings $(0.095 \pm 0.029)$ and all 60 near-natural grassland plots $(0.088 \pm 0.023)$.

\section{Bee surveys}

Sampling of each plot was performed during five sampling events evenly distributed between April to September 2018, starting with the flowering of dandelion and continuing every 3 to 4 weeks depending on weather conditions. Sampling was performed in resource-dependent variable transect walks (Westphal et al. 2008; Schindler et al. 2013). Accordingly, collectors could freely move with respect to the distribution of relevant nesting and feeding resources for bees within the plots. On structure-rich plots, which covered a variety of habitat elements, small habitat patches were sampled for a maximum of $5 \mathrm{~min}$. Sampling was performed by wild bee experts (see acknowledgements) to guarantee reliable species determination. To account for intra-day bee phenology, bees were collected during two subunits of $25 \mathrm{~min}$, one before and one after 12:30, respectively, with a minimum of $120 \mathrm{~min}$ in between at each sampling event. All observed bee individuals were caught with an entomological net, except for those that could be determined at first sight and identified to species level in the field (following Colla and Packer 2008; Krauss et al. 2009; Kratschmer et al. 2018 and others). Sampling time was stopped if prolonged handling of the bees became necessary. Bee sampling was only conducted during sunny weather (cloud cover less than $30 \%$ ), temperatures above $13{ }^{\circ} \mathrm{C}$ and low wind conditions. Any individuals that could not be identified to species level in the field were euthanized and subsequently identified by the wild bee taxonomist who had collected them.

Local plant availability

Before and during each bee survey, all flowering plant species encountered that might act as a potential feeding source for bees were recorded. Furthermore, total flower cover (of all species combined) was assessed on a scale of 1-4 for the entire plot, with 1 representing flower cover of less than 1 percent and with 4 representing flower cover of more than $40 \%$. Voucher specimens of plants that could not be identified to species level on the spot were determined in the laboratory.

\section{Landscape composition}

The landscape composition was mapped in each of the 20 study areas. Habitat types were recorded in a 500-m radius around a centroid, which was calculated from the centroid positions of all of the nine sampling plots in each study area. This radius was chosen because landscape context has been shown to affect species richness and the abundance of bees at relatively small spatial scales within a radius of about 300 to $750 \mathrm{~m}$ (Steffan-Dewenter et al. 2002; Kohler et al. 2008; Zurbuchen and Müller 2012). Of the 180 sampling plots, 157 were situated inside the 500-m radius, whereas the remaining 23 plots were in close proximity (less than $350 \mathrm{~m}$ ) to the mapped area. We did not evaluate landcover separately for each plot because high-resolution landscape mapping is extremely timeconsuming. However, the position of plots within the respective radii did not bias our results (see Supplementary Material for details). Following SteffanDewenter et al. (2002), we defined seven individual habitat types that were used to classify mapped areas: settlement area (including sealed surfaces), arable land, intensively managed grassland (species-poor nutrient-rich grassland with high management 
intensity), extensively managed grassland (regularly managed grassland reflecting naturally given habitat conditions, e.g. calcareous grassland and extensively managed nutrient-rich grassland), ruderal areas (minimally managed but open areas that were not used for agricultural production, with a dominance of perennial tall forbs), woodland edges (1.5-m deep boundary around hedges and woodland area) and field margins (0.5-m boundary around agricultural land) (see Supplementary Material Table S5 for minimum, maximum and mean cover of all landscape variables). The two last mentioned categories were calculated by multiplying the edge length of woodland and agricultural land with the respective boundary width. The habitat type ruderal areas was the only one that consisted of multiple small patches distributed in the landscapes. Waterbodies were excluded from our analyses, as they were believed to have neither positive nor negative effects on the bees covered by our field surveys (Westrich 1989). We included woodland edges but not forest area in our models as forest edge has been predicted to have a stronger effect on bee communities than core areas of boreal forest (Mandelik et al. 2012; Rubene et al. 2015; Roberts et al. 2017; Wu et al. 2019) and this habitat type was less prone to collinearity with other landscape variables. The digitization of survey data and the geographical calculation of field and woodland edge length were performed with the QGIS 2.18.28 (Quantum GIS Development Team 2014) software based on a combination of orthographical images provided by the state of Baden-Wuerttemberg and Google satellite basemaps (accessed 10 February 2018). Boundaries of single habitat patches were defined by QGIS and adjusted during the field surveys.

\section{Statistical analysis}

Individual-based species accumulation curves were created to compare species richness and abundance between near-natural grassland, flower plantings and residual habitat elements. Thus, bee data were aggregated within each habitat type and accumulation curves were calculated by using the package iNEXT (Hsieh et al. 2016). This approach was applied as it has been shown not only to compare sheer species number, but also to incorporate compositional heterogeneity between sites (Crist and Veech 2006; Neumüller et al. 2018). Statistical significance between accumulation curves was determined after MacGregor-Fors and Payton (2013). In order to explore species turnover between and within study plots, composition data were standardized by calculating the proportion that each bee species contributed to the total number of sampled bee individuals on a sampling plot. To explore compositional heterogeneity between sites, we used the vegdist function (Oksanen 2007) to calculate the Bray-Curtis dissimilarity between individual sampling plots and the betadisper function (Oksanen 2007) to calculate the dispersion of each group. Subsequently the permutetest function (Oksanen 2007) with 10,000 permutations was used to compare dispersions between the three groups. To compare species composition between habitat types directly, we performed a pairwise permutational multivariate analysis of variance (PERMANOVA) using the pairwise.adonis function (Arbizu 2020). To explore species that contribute to the compositional dissimilarity between the three habitat categories, we additionally performed a pairwise simper analysis (Oksanen 2007).

To evaluate the response of bee communities in the various habitat types to landscape composition and local floral availability on the sampling plots, data were split up into three seasons: early (including sampling events one and two), mid (including sampling event three) and late (including sampling events four and five) season. We calculated two individual models for each of the three seasons, by using either bee species richness or bee abundance as the dependent variable. Species and individual numbers of the five sampling events were totalled within each of the 180 sites. We log-transformed numbers of individuals and square root-transformed species counts to normalize count data. Data from the vegetation surveys were pooled by taking the mean richness and cover of flowering plants per site. Hence, mid-points of flowercover categories were averaged per site (for detailed methodology see Supplementary Material). All predictor variables were z-transformed by using the function scale implemented in the $\mathrm{R}$ base package. To test for a spatial dependence of our bee data derived from the distribution of our sampling regions, we followed Zuur et al. (2017) and fitted experimental variograms on the bee data as implemented in the package geoR (Ribeiro Jr and Diggle 2018). The variograms indicated spatial dependences, as was later confirmed by a reduction of AICc values in the regression models when a spatial correlation structure 
was added. Given the detected spatial dependency and the need for post-hoc slope comparisons, we extracted the centroid-coordinates of each sampling site and included them as a spatial correlation structure into multiple linear regression models by using generalized least squares (GLS) as implemented in the package nlme (Bates and Pinheiro 1998). By adding the spatial correlation structure to the models, we accounted for spatially dependent climatic differences between the 20 research regions (Zuur et al. 2010). To avoid collinearity, we calculated variance inflation factors (vif) as implemented in the package car (Fox and Weisberg 2011) and stepwise excluded the most collinear variables until no variable had a vif-value over 3 (Zuur et al. 2007, 2010). This threshold was reached after exclusion of the factors arable land and settlement area. Because of the strong negative correlation (Pearson correlation coefficients $\leq-0.60$ ) of arable land with near-natural grassland and settlement area with woodland edges (see Supplementary Material Fig. S2), the two landscape variables were nonetheless represented in our model.

After the basic model structure was determined, we employed full models containing mean flower cover and mean flower richness to represent local habitat conditions and the remaining five landscape variables as independent variables, while setting transformed numbers of bee species or individuals as the response variable. Furthermore, to test whether the three habitat types of near-natural grassland, flower plantings and residual habitat elements reacted differently to the local flower availability and landscape composition, we set all independent variables in an interaction with habitat type. Using the function emtrends implemented in the package emmeans (Lenth et al. 2019), we calculated coefficient estimates for each habitat type from the full models (for detailed methodology see https://cran.r-project.org/web/packages/emmeans/ vignettes/interactions.html). As confidence intervals should not be used to perform slope comparisons (Lenth 2016), we performed a post-hoc test for a pairwise comparison of the estimate slopes of the three habitat types as implemented in the package emmeans (Lenth et al. 2019).

To evaluate whether effects for the individual habitats were also detected when bee data of the three habitat types were totalled, we created three global models for bee richness and abundance containing the totalled data of all three habitat types for each of the three seasons. Here, we applied the same fitting process as described for the previous models, except that the interaction with habitat type was omitted. To ensure a sufficient fit of our models, diagnostic residual plots were inspected for each of the regression models. In all models transformed data met the assumptions of the model. To test whether landscape complexity showed a continuous gradient over Germany, we inspected a contour plot that illustrated the way that landscape diversity is driven by the spatial position of the landscapes. No such spatial trend was detected.

Estimated values for species richness and abundance showed strikingly congruent patterns. Furthermore, slope differences detected for abundance were an exact subset of the slope differences detected for species richness. Therefore, we decided only to present regression results for the models including bee species richness (regression results for bee abundance are given in the Supplementary Material Fig. S3).

To investigate the influence of landscape composition on species turnover within the three habitat types, we calculated a PERMANOVA by using the function Adonis implemented in the vegan package (Oksanen 2007). Subsequently, we tested the standardized data matrix against the five landscape variables in an interaction with habitat type as independent variables. For this analysis, we also standardized composition data by calculating the proportion that each bee species contributed to the total number of sampled bee individuals on a sampling plot.

To test whether the shape of a habitat patch influenced the reaction of the inhabiting bee community to the surrounding landscape, we calculated the edge to surface area ratio of all residual habitat plots. Subsequently, we created a GLS models following the same modelling approach as for the previous models with species richness as the dependent variable, except that we set an interaction between all landscape variables and the edge to surface area ratio. 


\section{Results}

Across all 180 sites, we recorded a total of 27,650 wild bees belonging to 324 species, representing about $57 \%$ of all known German bee species (Westrich 2018).

Bee species richness was similar between nearnatural grasslands and residual habitats (strongly overlapping confidence intervals of species accumulation curves, Fig. 2). In contrast, the species accumulation curve of flower plantings indicated that species richness over all sites was significantly lower than on the other two habitat types. On flower plantings, we recorded 11,638 bees, followed by 10,663 bees on near-natural grassland and 6874 bees on residual habitat elements (Fig. 2). Compositional heterogeneity between sampling plots was highest in residual habitats, exceeding that in near-natural grassland and flower plantings (Fig. 3). Furthermore, near-natural grassland showed a higher compositional heterogeneity than flower plantings. Similar to the results concerning compositional heterogeneity, species composition differed between all three habitat types. Although explained variation was generally low $(<7 \%)$, differences between flower plantings and near-natural grassland and between flower plantings and residual habitats were about double that of nearnatural grassland and residual habitats (Table 1). The simper analysis revealed, that compositional differences between habitat types were predominately caused by common generalist species such as Bombus

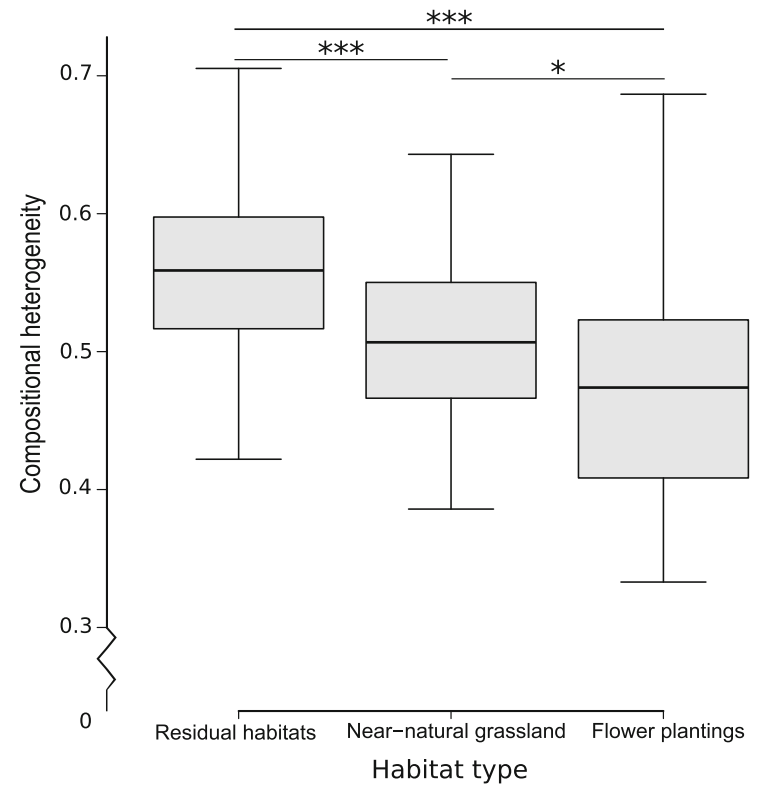

Fig. 3 Comparison of compositional heterogeneity in the three habitat types. Boxes represent the median and 25 th/75th percentile of the distances to the group centroid derived from betadisper. Whiskers extend to 1.5 times the interquartile range. Bars with asterisks indicate significant differences in compositional heterogeneity: $* \mathrm{p}<0.05$. $* * \mathrm{p}<0.01$. *** $\mathrm{p}<0.001$

lapidarius, Andrena flavipes and Laioglossum malachurum, that occurred on all three habitat types but fluctuated in abundance (for further information see Supplementary Material).
Fig. 2 Individual-based randomized species accumulation curves comparing wild bee richness between the three habitat types. The shaded areas represent $95 \%$ confidence intervals

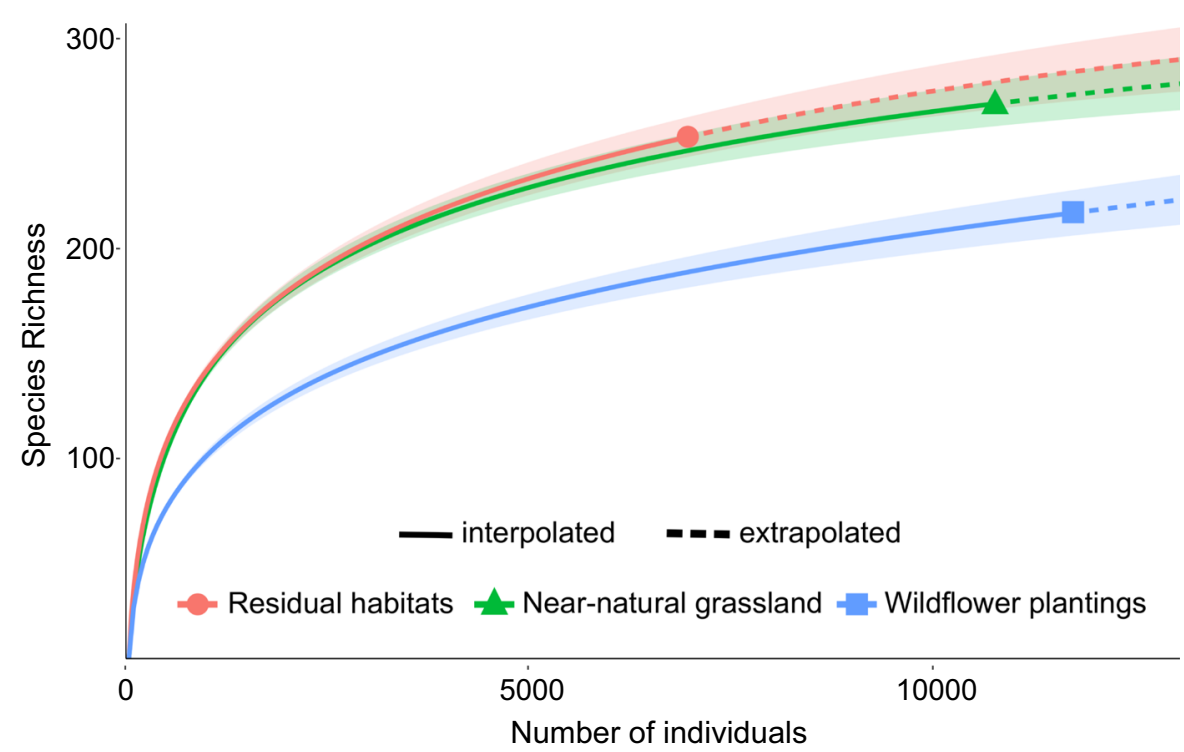


Table 1 Pairwise PERMANOVA comparing species composition between the three habitat types

\begin{tabular}{lllll}
\hline Habitat comparison & Df & Pseudo-F & $\mathrm{R}^{2}$ & $\mathrm{p}$ \\
\hline Residual habitats $\times$ near-natural grassland & 1 & 2.808 & 0.023 & $<\mathbf{0 . 0 0 1}$ \\
Residual habitats $\times$ flower plantings & 1 & 5.686 & 0.046 & $<\mathbf{0 . 0 0 1}$ \\
Near-natural grassland $\times$ flower plantings & 1 & 7.477 & 0.060 & $<\mathbf{0 . 0 0 1}$ \\
\hline
\end{tabular}

Significant p-values in bold

In the local vegetation surveys, we recorded 449 different flowering plant species that were a potential feeding source for bees. The mean richness of flowering plants was highest on near-natural grassland $(\overline{\mathrm{x}}=30.7, \mathrm{SD}=9.3$ species $)$ and was similar for flower plantings $(\overline{\mathrm{x}}=25.1, \mathrm{SD}=5.4)$ and residual habitats $(\overline{\mathrm{x}}=25.3, \mathrm{SD}=8.1)$.

\section{Effects of local habitat conditions}

The number of flowering plant species had an overall significant positive effect on bee species richness in the global models (containing data of all three habitat types) over all three sampling seasons (Fig. 4a-c). Comparisons between habitat types revealed that, in the late season, bee species richness in flower plantings was more strongly driven by flowering plant species richness than on near-natural grassland and residual habitat patches. Additionally, bee species richness increased with mean local flower cover over all the three seasons and no slope differences between the habitat types were detected. The shape of the residual habitat plots did not affect the way that the inhabiting bee community reacted to the surrounding landscape (Table 2).

\section{Effects of landscape composition}

The model results discussed in this paragraph are summarized in Fig. 4. The proportional cover of the surrounding ruderal areas positively affected bee species richness in the early and mid-season global models. Ruderal areas showed overall positive effect sizes in near-natural grassland, whereas flower plantings in the early season and residual areas in the late season showed estimates that were close to zero and that differed significantly from the positive effect sizes in near-natural grassland. The cover of extensively managed grassland also enhanced species richness in the early- and mid-season global models. In residual habitats, the positive effect of extensively managed grassland was significantly more pronounced than that of near-natural grassland (early- and late season) and flower plantings (late season). Additionally, in flower plantings the positive effect of surrounding extensively managed grassland was more strongly pronounced than in near-natural grassland during the early season. In the global models, the cover of woodland edges positively contributed to bee species richness only during the late season. Near-natural grassland was particularly unaffected by woodland edges in the surrounding landscape and showed significantly lower estimates than flower plantings (early season) and residual habitats (late season). The extent of field margins did not yield a significant response in any of the global models but produced significantly different effect sizes between habitat types. In the early season, residual habitats showed a significantly more negative response to field margins than near-natural grassland and flower plantings. In contrast, flower plantings showed significant and more positive response to field margins during the midseason. The cover of intensively managed grassland showed a consistent negative effect on bee species richness over all seasons and habitat types. This negative effect was also apparent in the global models, although, in the late season, confidence intervals were inflated, leading to a similar but not significant estimate.

All landscape variables showed a highly significant effect on species composition (Table 3). Nevertheless, each landscape variable explained only a small proportion $(<6 \%)$ of the total variance in the dataset. Intensively managed grassland and ruderal areas showed a significant interaction with habitat type but the explained variation for each interaction was small $(<1.5 \%)$. 
A Early-season
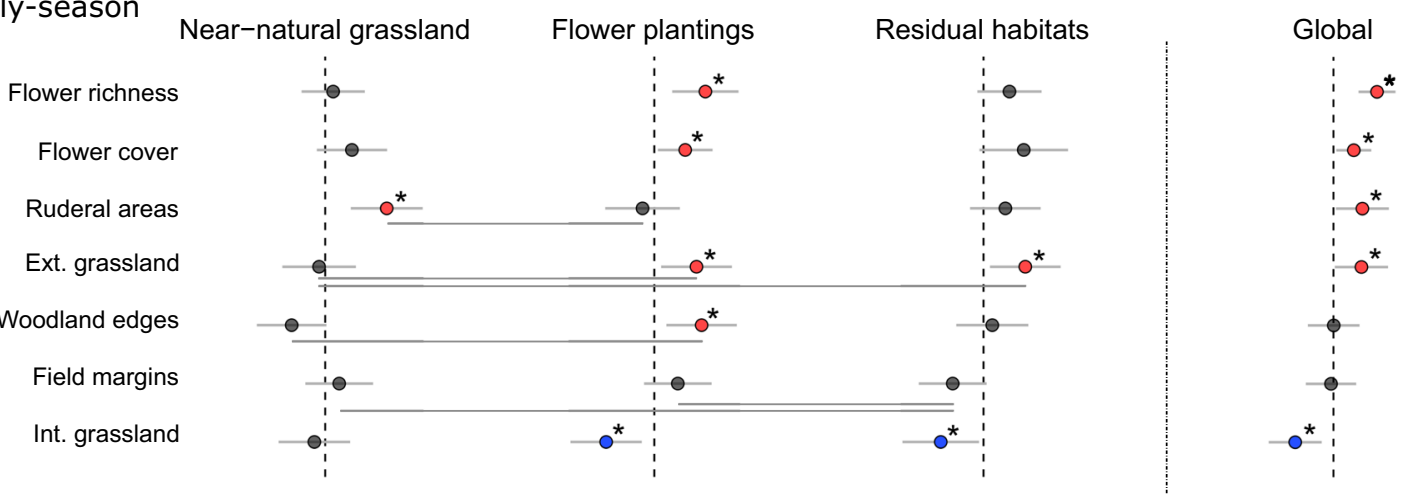

B Mid-season

Flower richness

Flower cover

Ruderal areas

Ext. grassland

Woodland edges

Field margins

Int. grassland

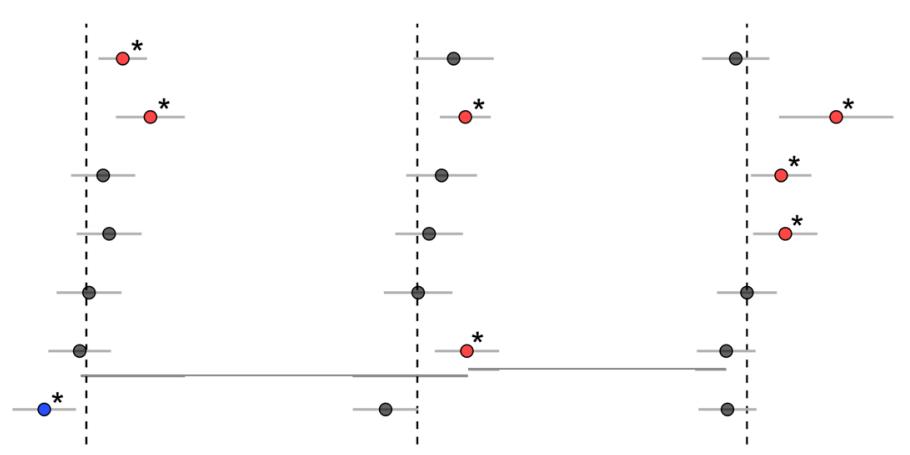

C Late-season

Flower richness

Flower cover

Ruderal areas

Ext. grassland

Woodland edges

Field margins

Int. grassland
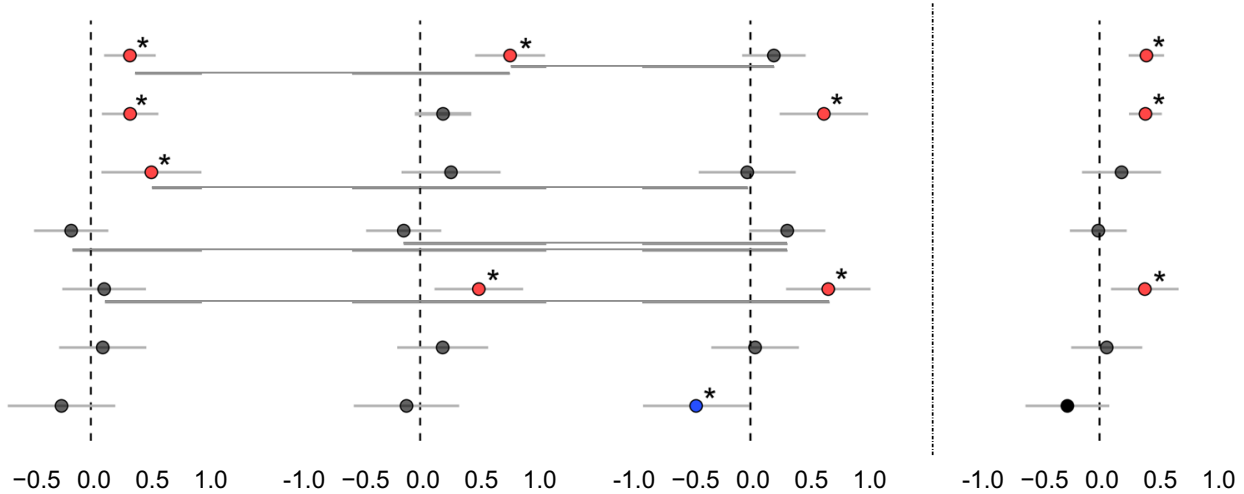

Fig. 4 Effects of local and landscape factors on wild bee species richness. Estimated slopes are predicted from the GLS regression models with a spatial dependency structure. Dots and bars show standardized effect sizes with 95\% confidence intervals of the two local (flower species richness and cover) and five landscape parameters on wild bee richness during the early (a), mid (b) and late (c) seasons. Global models show effect sizes for a model combining data of all three habitat types, without consideration of habitat type in the modelling structure.

\section{Discussion}

The composition of the surrounding agricultural landscape and the local flower availability moderated
Effects where confidence intervals do not overlap zero are marked with an asterisk to indicate significance. Bars beneath a pair of effects indicate significantly different $(p<0.05)$ effect sizes between two habitat types in the models that include habitat as an interaction term. All models with regard to single habitat types have 150 degrees of freedoms; all global models have 172 degrees of freedoms. The complete model output is given in the Supplementary Material (Table S3 \& Table S4)

wild bee communities in near-natural grassland, newly established flower plantings and residual habitats (potential bee habitats still present in agricultural 
Table 2 Results of the GLS regression model that tested whether the edge to surface area ratio of a residual habitat plot influenced how the inhabiting bee community reacts to the surrounding landscape

\begin{tabular}{|c|c|c|c|c|}
\hline & Estimate & $\mathrm{SE}$ & $\mathrm{t}$ & $\mathrm{p}$ \\
\hline Flower species & 0.301 & 0.215 & 1.399 & 0.168 \\
\hline Flower cover & 1.072 & 0.378 & 2.835 & 0.007 \\
\hline Ruderal areas: edge to surface ratio & 0.344 & 0.249 & 1.381 & 0.173 \\
\hline Ext. grassland: edge to surface ratio & 0.360 & 0.215 & 1.677 & 0.100 \\
\hline Woodland edges: edge to surface ratio & -0.048 & 0.204 & -0.234 & 0.816 \\
\hline Field margins: edge to surface ratio & -0.183 & 0.196 & -0.935 & 0.354 \\
\hline Int. grassland: edge to surface ratio & -0.337 & 0.295 & -1.144 & 0.258 \\
\hline
\end{tabular}

Significant $\mathrm{p}$-values in bold

Table 3 Nonparametric PERMANOVA testing how landscape composition drives species turnover

Double dots between a landscape variable and the habitat type indicate an interaction. Significant p-values in bold

\begin{tabular}{lrccc}
\hline & Df & Pseudo-F & $\mathrm{R}^{2}$ & $\mathrm{p}$ \\
\hline Int. grassland & 1 & 10.266 & 0.044 & $<\mathbf{0 . 0 0 1}$ \\
Ext. grassland & 1 & 8.207 & 0.035 & $<\mathbf{0 . 0 0 1}$ \\
Woodland edges & 1 & 6.361 & 0.027 & $<\mathbf{0 . 0 0 1}$ \\
Ruderal areas & 1 & 5.095 & 0.022 & $<\mathbf{0 . 0 0 1}$ \\
Field margins & 1 & 13.304 & 0.057 & $<\mathbf{0 . 0 0 1}$ \\
Habitat type & 2 & 6.483 & 0.056 & $<\mathbf{0 . 0 0 1}$ \\
Int. grassland: habitat type & 2 & 1.714 & 0.015 & $\mathbf{0 . 0 0 9}$ \\
Ext. grassland: habitat type & 2 & 1.265 & 0.011 & 0.13 \\
Woodland edges: habitat type & 2 & 1.149 & 0.01 & 0.244 \\
Ruderal areas: habitat type & 2 & 1.676 & 0.014 & $\mathbf{0 . 0 1}$ \\
Field margins: habitat type & 2 & 1.431 & 0.012 & 0.06 \\
Residuals & 162 & & 0.696 & \\
\hline
\end{tabular}

areas). Intensively managed grasslands often had a negative effect, whereas extensively managed areas such as woodland edges and ruderal areas showed a positive impact on species richness. However, the influence of the landscape elements on the different habitat types often varied and was most pronounced during the early and late sampling season. Bee richness in near-natural grassland showed a particularly positive response to ruderal areas. In flower plantings and residual habitats such as field margins bee richness showed a pronounced positive response to extensively managed grassland and woodland edges. In addition to the landscape, local floral resources played an important role in all three habitat types. Although community composition was primarily driven by other factors, landscape composition also played a role in shaping the studied bee communities.
Effects of local habitat conditions on bee richness

In accordance with numerous other studies (SteffanDewenter and Tscharntke 2001; Holzschuh et al. 2007), in our investigation the richness of flowering plant species within habitat types had a highly significant effect on bee species richness over all three habitat types in the early, mid and late sampling season. As hypothesized, the numbers of bee species were particularly strongly influenced by floral species richness in flower plantings. The flower plantings were recently established and a limited number of mainly annual plant species bloomed during the first year, when our study was performed. In particular, one plant species, Anthemis tinctoria, dominated most of the flower plantings later in the year, which certainly led to the particularly strong response of bee species 
richness to flowering plant species richness during the late season.

Local habitat conditions also influenced residual habitats that hosted a large number of bee species indicated by the calculated species accumulation curves. Residual habitats represented a openly defined habitat category, and some of them consisted of areas with ruderal vegetation while others were managed field margins. Differing disturbance (management) regimes result in distinct communities and therefore enhance beta diversity (Hawkins et al. 2015; Neumüller et al. 2018). Hence, the varying management regime in residual habitats certainly enhanced compositional heterogeneity and thereby increased the total number of bee species observed over all residual habitat plots.

In addition to flower richness, mean flower cover had a positive effect on wild bee species richness and abundance over all three habitat types in the early, mid- and late-sampling season. Sites with high flower cover are able to attract more bee species and individuals from the surrounding metacommunity (Westphal et al. 2003; Kratschmer et al. 2019). Taken together, our findings are in accordance with previously existing data and support the evidence that wild bee communities strongly depend on local floral resources. Hence, we advise the incorporation of flower cover and richness when modelling wild bee data. Furthermore, the phenology of individual plant species is crucial for ensuring constantly high flower cover in flower plantings throughout the season.

Although species composition differed between the three habitat categories, the proportion of explained variation in the whole dataset was rather low. Furthermore, differences were mostly driven by dissimilarities in abundances of common species. Beside the described differences, compositional effects were mainly explained by the region in which wild bee data was acquired. Wild bees built local communities with low alpha-diversity but show a high species turnover over a wide spatial extent (Rubene et al. 2015). In our large-scale study, this turnover was probably driven by different climatic conditions in our research areas. A study design in which sample plots are less spatially dispersed would certainly facilitate composition caparisons between habitat categories.
Effects of landscape composition on wild bee richness

\section{Extensively managed grassland}

In general, extensively managed grassland is of high quality for wild bees (Meyer et al. 2017) and has positive spill-over effect on bee communities in the surrounding landscape (Albrecht et al. 2007). However, the proportion of extensive grassland in our research areas did not affect bee richness on the surveyed near-natural grassland plots. These plots were embedded into large meadows, possibly making them relatively independent of management events in the surroundings. In contrast, a positive effect of extensive grassland was significantly more pronounced on residual habitats and flower plantings than on the near-natural grassland plots. In flower plantings, a positive effect of extensively managed grassland was only present during the early-season. This indicates that extensively managed grassland acts as an important source area for newly established flower plantings in the beginning of the season, but that the later importance of this landscape variable diminishes.

\section{Arable land}

The positive effect of extensive grassland can also be ascribed to the associated reduction of intensive arable farming (Kremen et al. 2002), as we have found that the proportion of extensively managed grassland is negatively correlated with those of arable land in the studied surroundings. In this context, an increased cover of tilled agricultural land has been shown to reduce bee richness and abundance by reducing floral resources on a landscape scale (Le Féon et al. 2010; Ahrenfeldt et al. 2019). Furthermore, pesticide seedcoating and spray drift on arable land can contaminate nearby non-target areas (Pimentel 1995; Brittain et al. 2010; Botías et al. 2016).

\section{Ruderal areas}

During field inspections and the mapping of the landscapes, we were able to record small patches of landscape elements, such as ruderal areas, that are spread within and between landscape elements. These patches had a significantly positive effect on species 
richness particularly in near-natural grassland but also in residual habitats. Ruderal areas in an advanced state of succession provide high flower densities of diverse herbs and thereby promote a different set of bee species compared with those of regularly-managed habitat types (Gathmann et al. 1994; Steffan-Dewenter and Tscharntke 2001). In addition to food sources, perennial plants represent vital nesting resources for many cavity nesting bees (Westrich 2018). Persistent and extensively managed sites are also beneficial for ground-nesting bees, as nesting sites can exist for many years. As a result, irregularly managed ruderal habitat patches might act as refuge habitats when extensive mowing or grazing leads to a decline of feeding and nesting sources on managed grassland (Mandelik et al. 2012). High-quality ruderal habitat patches might also represent stepping stones enabling bees to disperse through an otherwise unsuitable or even hostile landscape matrix (Kimura and Weiss 1964). Therefore, ruderal areas seem to be highquality habitats that probably act as source habitat for the species pool of a landscape (Pulliam 1988). The promotion of patches with ruderal vegetation is therefore a promising approach for supporting bee communities in near-natural grasslands.

\section{Woodland edges}

In our study, woodland edges positively affected bee species richness on flower plantings during the early and late seasons, whereas residual habitats were positively affected during the late season only. In contrast, no clear trend was observed for near-natural grassland. As the flower plantings had been newly established on arable land, which had probably not been colonized before by many bee species, this habitat type strongly depended on source areas with a high bee diversity. Woody plants provide abundant feeding resources, at least for generalist bees (Mallinger et al. 2016; Hausmann et al. 2016). Furthermore, they provide resources for cavity nesting bees and nesting materials for those species that require plant parts to build their nests (Westrich 2018). On the other hand, woody landscape elements have been shown to function as barriers that obstruct the movement and dispersal of wild bees (Klaus et al. 2015) and can therefore negatively influence wild bee populations. This factor may have played a role in our study, as some of our research areas were interspersed with large woodland bodies or even encircled by forest. Protected meadow bodies are particularly affected by isolation (Piessens et al. 2005). Consequently, the positive effect of woodland edges on the habitat type near-natural grassland might have been mitigated by isolation effects.

\section{Field margins}

Field margins can have the opposite effect of woodland barriers, as they may act as corridors that can enhance species mobility in a landscape (Jauker et al. 2009). Nevertheless, field margins are often intensively managed and highly degraded. In accordance with the contrasting properties, the landscape variable field margins showed significant discrepancies in the effect sizes between habitat types, and global models did not detect any clear trend. Composition analysis revealed that field margins had the strongest effect on species composition. This suggests that field margins alter species composition either directly by spill-over to the surrounding landscape or indirectly by enhancing species mobility in a landscape. In this context it was shown, that corridors increase connectivity in fragmented agricultural landscapes (Steffan-Dewenter et al. 2002).

\section{Intensively managed grassland.}

Although not always statistically significant, intensively managed grassland showed a consistent negative effect at sites in all habitat types, and all three global models showed similar negative estimates. Intense grassland is characterized by frequent management activities and the associated decline of flowers which prevent mass occurrences of bees (Meyer et al. 2017). Moreover, bees can be crushed by cutting machines during mowing events (Fluri and Frick 2002; Humbert et al. 2010). These factors might have also reduced the bee abundance at the landscape level in our study. Intense management practices can also reduce wild bee diversity (Albrecht et al. 2007; Wastian et al. 2016) by excluding bees that are not adapted to frequent disturbances and the related vegetation (Steffan-Dewenter and Tscharntke 2001). In agreement with this idea, intensively managed grassland had the second highest influence on species composition. Different disturbance regimes result in distinct plant communities that in turn shape wild bee 
communities (Hawkins et al. 2015; Neumüller et al. 2018). In this context it has been shown, that intensively managed agricultural landscapes are dominated by generalist ground-nesting bee species (Ahrenfeldt et al. 2019). In concordance with this assumption, generalist ground-nesting species such as certain species of bumblebees, halictid bees and andrenid bees substantially contributed to the compositional dissimilarity between the three habitat types. Taken together with the positive effect that extensively managed grassland has on bee richness, a reduction of management intensity on grassland certainly will have a consistently positive effect on wild bee communities over a variety of habitat types.

Seasonal patterns of landscape effects

As hypothesized, some of the described landscape effects on wild bees followed seasonal patterns. Woodland edges positively affected bee species richness in the early- and late-season. In a recent study it was shown that blooming woody plants provide abundant feeding resources in spring (Mallinger et al. 2016). As a result, the abundance of early flying bees is positively correlated to the percentage of tree cover in a landscape (Banaszak-Cibicka and Żmihorski 2012). Above that, we found that woodland edges positively influenced bees also in the lateseason. Compared with open sites, woodland edges provide a more stable climatic environment throughout the year, with lower temperature maxima in the summer (Morecroft et al. 1998). As a result, woodland edges may buffer unfavourable temperature peaks (Kühsel and Blüthgen 2015) during the heat of the late-season that can negatively influence daily activity patterns of bees and also food availability (Phillips et al. 2018).

Extensively managed grassland positively affected wild bee richness in the early- and mid-season, while there was no clear effect in the late-season. High temperatures and low precipitation during the late season probably reduced floral resources in the surrounding extensively managed grassland (Phillips et al. 2018) whereby the positive effect on wild bees became lost. Furthermore, extensively managed grassland was predominately managed during the lateseason what additionally reduced floral resources during this time of the year.
Effect of habitat shape

Wild bee communities in near-natural grassland were only affected by two landscape elements, ruderal areas and intensively managed grassland. Otherwise, the response of near-natural grassland to the landscape elements was mostly neutral. In contrast, residual habitats and flower plantings showed a more profound response to a greater variety of landscape variables. Even though the edge to surface ratio did not explain the reaction of the residual habitats to landscape composition as hypothesized, flower plantings and residual habitats stood in a stronger relationship with the surrounding landscape than near-natural grassland plots. Near-natural grassland plots were mostly situated on the edge of a greater grassland body but the connection to the adjacent landscape was obviously diminished by the large proportion of near-natural grassland surrounding them. In this context, a relatively short distance of homogenous habitat has been shown to efficiently isolate bee communities from the surrounding landscape (Bailey et al. 2014). Although the sampled patches in this study were probably too small to detect a considerable effect of the edge to surface ratio, we concur that a large extent of homogenous habitat will isolate an embedded habitat patch from the surrounding landscape. This effect can potentially be beneficial when the neighbouring landscape matrix is hostile, but may also decelerate favourable spillover effects from the surrounding landscape matrix.

\section{Conclusion}

Bee communities in the three habitat types that we investigated responded positively to local flower availability. Above that, we showed that landscape features differently impact bee communities of different habitat types. Furthermore, landscape effects were particularly pronounced during early and late season. Consequently, effects of landscape variables on bee communities might be underestimated when not controlling for local habitat conditions and seasonality. We have found no evidence that the edge to surface area ratio of a habitat patch influences the response of wild bee communities to the landscape composition, although this result should be verified with a specified study design. For wild bee 
conservation, a reduction of the intensity of grassland management will be a promising approach to improve bee diversity in a broad range of habitat types. In addition, the promotion of ruderal areas or woodland edges represents an opportunity to support wild bee communities in specific habitat categories.

Acknowledgements We thank H. R. Schwenninger who was substantially involved in setting up and running the BienABest project, L. Woppowa (VDI e.V.) and H Seitz (VDI e.V.) for coordination of the BienABest project, H. R. Schwenninger, R. Burger, O. Diestelhorst, J. C. Kornmilch, C. Saure, A. Schanowski and E. Scheuchl for conducting bee sampling and determination, K. Weiss, M. Weiss and all stakeholders for their role in establishing flower plantings. M. Gillingham helped us with the statistical evaluation of data and J. Kuppler gave valuable comments on the manuscript. We thank R. Prosi for his contribution in data handling. The project "BienABest" of the VDI Society Technologies of Life Sciences and the University of Ulm is funded by the Federal Agency for Nature Conservation $(\mathrm{BfN})$ in the Federal Programme for Biological Diversity with funding from the Federal Ministry for the Environment, Nature Conservation and Nuclear Safety (BMU). The project is financially supported by the Ministry of the Environment, Climate Protection and the Energy Sector BadenWürttemberg, BASF SE, and the Bee Care Center of Bayer AG.

Funding Open Access funding provided by Projekt DEAL.

\section{Compliance with ethical standards}

Conflict of interest The authors declare that they have no conflict of interest.

Open Access This article is licensed under a Creative Commons Attribution 4.0 International License, which permits use, sharing, adaptation, distribution and reproduction in any medium or format, as long as you give appropriate credit to the original author(s) and the source, provide a link to the Creative Commons licence, and indicate if changes were made. The images or other third party material in this article are included in the article's Creative Commons licence, unless indicated otherwise in a credit line to the material. If material is not included in the article's Creative Commons licence and your intended use is not permitted by statutory regulation or exceeds the permitted use, you will need to obtain permission directly from the copyright holder. To view a copy of this licence, visit http://creativecommons.org/licenses/by/4.0/.

\section{References}

Ahrenfeldt EJ, Kollmann J, Madsen HB, Skov-Petersen H, Sigsgaard L (2019) Generalist solitary ground-nesting bees dominate diversity survey in intensively managed agricultural land. J Melittology. https://doi.org/10.17161/jom. v0i82.7057
Albrecht M, Duelli P, Müller C, Kleijn D, Schmid B (2007) The Swiss agri-environment scheme enhances pollinator diversity and plant reproductive success in nearby intensively managed farmland. J Appl Ecol 44:813-822

Arbizu M (2020) pairwiseAdonis: Pairwise multilevel comparison using adonis. R package version 0.4 . https://github. com/pmartinezarbizu/pairwiseAdonis. Accessed 15 Jun 2020

Bailey S, Requier F, Nusillard B, Roberts SP, Potts SG, Bouget C (2014) Distance from forest edge affects bee pollinators in oilseed rape fields. Ecol Evol 4:370-380

Banaszak-Cibicka W, Żmihorski M (2012) Wild bees along an urban gradient: winners and losers. J Insect Conserv 16:331-343

Banaszak J (1992) Strategy for conservation of wild bees in an agricultural landscape. Agric Ecosyst Environ. https://doi. org/10.1016/0167-8809(92)90091-O

Bates DM, Pinheiro JC (1998) Linear and nonlinear mixedeffects models. Conf Appl Stat Agric. https://doi.org/10. 4148/2475-7772.1273

Battin J (2004) When good animals love bad habitats: ecological traps and the conservation of animal populations. Conserv Biol 18:1482-1491

Biesmeijer JC, Roberts SPM, Reemer M, Ohlemüller R, Edwards M, Peeters T, Schaffers AP, Potts SG, Kleukers R, Thomas CD, et al (2006) Parallel declines in pollinators and insect-pollinated plants in Britain and the Netherlands. Science 313:351-354

BKG (2013) Digitales Geländemodell Gitterweite 200 m. https://www.geodatenzentrum.de/geodaten/gdz_rahmen. gdz_div?gdz_spr=deu\&gdz_akt_zeile=5\&gdz_anz_zeile= $1 \& g d z \_u n t \_z e i l e=3 \& g d z \_u s e r \_i d=0$. Accessed 21 May 2019

Blaauw BR, Isaacs R (2014) Flower plantings increase wild bee abundance and the pollination services provided to a pollination-dependent crop. J Appl Ecol 51:890-898

Bommarco R, Biesmeijer JC, Meyer B, Potts SG, Pöyry J, Roberts SP, Steffan-Dewenter I, Öckinger E (2010) Dispersal capacity and diet breadth modify the response of wild bees to habitat loss. Proc R Soc B Biol Sci 277:2075-2082

Bommarco R, Marini L, Vaissière BE (2012) Insect pollination enhances seed yield, quality, and market value in oilseed rape. Oecologia 169:1025-1032

Botías C, David A, Hill EM, Goulson D (2016) Contamination of wild plants near neonicotinoid seed-treated crops, and implications for non-target insects. Sci Total Environ 566-567:269-278

Brittain CA, Vighi M, Bommarco R, Settele J, Potts SG (2010) Impacts of a pesticide on pollinator species richness at different spatial scales. Basic Appl Ecol 11:106-115

Bystriakova N, Griswold T, Ascher JS, Kuhlmann M (2018) Key environmental determinants of global and regional richness and endemism patterns for a wild bee subfamily. Biodivers Conserv 27:287-309

Chopra SS, Bakshi BR, Khanna V (2015) Economic dependence of U.S. industrial sectors on animal-mediated pollination service. Environ Sci Technol 49:14441-14451

Colla SR, Packer L (2008) Evidence for decline in eastern North American bumblebees (Hymenoptera: Apidae), with 
special focus on Bombus affinis Cresson. Biodivers Conserv 17:1379-1391

Crist TO, Veech JA (2006) Additive partitioning of rarefaction curves and species-area relationships: unifying $\alpha-, \beta$ - and $\gamma$-diversity with sample size and habitat area. Ecol Lett 9:923-932

Ewers RM, Didham RK (2006) Confounding factors in the detection of species responses to habitat fragmentation. Biol Rev Camb Philos Soc 81:117-142

Fluri P, Frick R (2002) Honey bee losses during mowing of flowering fields. Bee World 83:109-118

Fox J, Weisberg S (2011) An R companion to applied regression. Sage, Thousand Oaks

Gathmann A, Greiler HJ, Tscharntke T (1994) Trap-nesting bees and wasps colonizing set-aside fields: succession and body size, management by cutting and sowing. Oecologia 98:8-14

Goulson D (2013) An overview of the environmental risks posed by neonicotinoid insecticides. J Appl Ecol 50:977-987

Grab H, Branstetter MG, Amon N, Urban-Mead KR, Park MG, Gibbs J, Blitzer EJ, Poveda K, Loeb G, Danforth BN (2019) Agriculturally dominated landscapes reduce bee phylogenetic diversity and pollination services. Science 363:282-284

Hass AL, Kormann UG, Tscharntke T, Clough Y, Baillod AB, Sirami C, Fahrig L, Martin J-L, Baudry J, Bertrand C et al (2018) Landscape configurational heterogeneity by smallscale agriculture, not crop diversity, maintains pollinators and plant reproduction in western Europe. Proc R Soc B Biol Sci. https://doi.org/10.1098/rspb.2017.2242

Hausmann SL, Petermann JS, Rolff J (2016) Wild bees as pollinators of city trees. Insect Conserv Divers 9:97-107

Hawkins CP, Mykrä H, Oksanen J, Vander Laan JJ (2015) Environmental disturbance can increase beta diversity of stream macroinvertebrate assemblages. Glob Ecol Biogeogr 24:483-494

Holzschuh A, Dudenhöffer JH, Tscharntke T (2012) Landscapes with wild bee habitats enhance pollination, fruit set and yield of sweet cherry. Biol Conserv 153:101-107

Holzschuh A, Steffan-Dewenter I, Kleijn D, Tscharntke T (2007) Diversity of flower-visiting bees in cereal fields: Effects of farming system, landscape composition and regional context. J Appl Ecol 44:41-49

Hopfenmüller S, Steffan-Dewenter I, Holzschuh A (2014) Traitspecific responses of wild bee communities to landscape composition, configuration and local factors. PLoS ONE 9:e104439

Hsieh TC, Ma KH, Chao A (2016) iNEXT: an R package for rarefaction and extrapolation of species diversity (Hill numbers). Methods Ecol Evol 7:1451-1456

Humbert JY, Ghazoul J, Sauter GJ, Walter T (2010) Impact of different meadow mowing techniques on field invertebrates. J Appl Entomol 134:592-599

Jauker F, Diekötter T, Schwarzbach F, Wolters V (2009) Pollinator dispersal in an agricultural matrix: opposing responses of wild bees and hoverflies to landscape structure and distance from main habitat. Landsc Ecol 24:547-555

Kearns CA, Inouye DW, Waser NM (1998) Endangered mutualisms: the conservation of plant-pollinator interactions. Annu Rev Ecol Syst 29:83-112
Kennedy CM, Lonsdorf E, Neel MC, Williams NM, Ricketts TH, Winfree R, Bommarco R, Brittain C, Burley AL, Cariveau D et al (2013) A global quantitative synthesis of local and landscape effects on wild bee pollinators in agroecosystems. Ecol Lett 16:584-599

Kershner EL, Bollinger EK (1996) Reproductive success of grassland birds at east-central Illinois Airports. Am Midl Nat 136:358

Kimura M, Weiss GH (1964) The stepping stone model of population structure and the decrease of genetic correlation with distance. Genetics 49:561-576

Klaus F, Bass J, Marholt L, Müller B, Klatt B, Kormann U (2015) Hedgerows have a barrier effect and channel pollinator movement in the agricultural landscape. J Landsc Ecol Repub 8:22-31

Kohler F, Verhulst J, Van Klink R, Kleijn D (2008) At what spatial scale do high-quality habitats enhance the diversity of forbs and pollinators in intensively farmed landscapes? J Appl Ecol 45:753-762

Kratochwil A (2003) Bees (Hymenoptera Apoidea) as key-stone species: specifics of resource and requisite urilisation in different habitar types. Berichte der Reinhold-Tüxen-Gesellschaft 15:59-77

Kratschmer S, Pachinger B, Schwantzer M, Paredes D, Guernion M, Burel F, Nicolai A, Strauss P, Bauer T, Kriechbaum $\mathrm{M}$ et al (2018) Tillage intensity or landscape features: what matters most for wild bee diversity in vineyards? Agric Ecosyst Environ 266:142-152

Kratschmer S, Pachinger B, Schwantzer M et al (2019) Response of wild bee diversity, abundance, and functional traits to vineyard inter-row management intensity and landscape diversity across Europe. Ecol Evol 9:4103-4115

Krauss J, Alfert T, Steffan-Dewenter I (2009) Habitat area but not habitat age determines wild bee richness in limestone quarries. J Appl Ecol 46:194-202

Kremen C, Williams NM, Thorp RW (2002) Crop pollination from native bees at risk from agricultural intensification. Proc Natl Acad Sci USA 99:16812-16816

Kühsel S, Blüthgen N (2015) High diversity stabilizes the thermal resilience of pollinator communities in intensively managed grasslands. Nat Commun 6:7989

Le Féon V, Schermann-Legionnet A, Delettre Y, Aviron S, Billeter R, Bugter R, Hendrickx F, Burel F (2010) Intensification of agriculture, landscape composition and wild bee communities: a large scale study in four European countries. Agric Ecosyst Environ 137:143-150

Lenth R, Herve M, Love J, Riebl H, Singmann H (2019) Estimated marginal means, aka least-squares means. https:// cran.r-project.org/web/packages/emmeans/emmeans.pdf. Accessed 20 Aug 2020

Lenth RV (2016) Least-squares means: the R package lsmeans. J Stat Softw. https://doi.org/10.18637/jss.v069.i01

MacGregor-Fors I, Payton ME (2013) Contrasting diversity values: statistical inferences based on overlapping confidence intervals. PLoS ONE 8:e56794

Mallinger RE, Gibbs J, Gratton C (2016) Diverse landscapes have a higher abundance and species richness of spring wild bees by providing complementary floral resources over bees' foraging periods. Landsc Ecol 31:1523-1535 
Mandelik Y, Winfree R, Neeson T, Kremen C (2012) Complementary habitat use by wild bees in agro-natural landscapes. Ecol Appl 22:1535-1546

Melathopoulos AP, Cutler GC, Tyedmers P (2015) Where is the value in valuing pollination ecosystem services to agriculture? Ecol Econ 109:59-70

Meyer S, Unternährer D, Arlettaz R, Humbert JY, Menz MH (2017) Promoting diverse communities of wild bees and hoverflies requires a landscape approach to managing meadows. Agric Ecosyst Environ 239:376-384

Morecroft MD, Taylor ME, Oliver HR (1998) Air and soil microclimates of deciduous woodland compared to an open site. Agric For Meteorol 90:141-156

Neumüller U, Pachinger B, Fiedler K (2018) Impact of inundation regime on wild bee assemblages and associated beeflower networks. Apidologie 49:817-826

Ogilvie JE, Forrest JR (2017) Interactions between bee foraging and floral resource phenology shape bee populations and communities. Curr Opin Insect Sci 21:75-82

Oksanen J (2007) Vegan: community ecology package. R package version $1.8-5$

Phillips BB, Shaw RF, Holland MJ, Fry EL, Bardgett RD, Bullock JM, Osborne JL (2018) Drought reduces floral resources for pollinators. Glob Chang Biol 24:3226-3235

Piessens K, Honnay O, Hermy M (2005) The role of fragment area and isolation in the conservation of heathland species. Biol Conserv 122:61-69

Pimentel D (1995) Amounts of pesticides reaching target pests: environmental impacts and ethics. J Agric Environ Ethics 8:17-29

Potts SG, Biesmeijer JC, Kremen C, Neumann P, Schweiger O, Kunin WE (2010) Global pollinator declines: trends, impacts and drivers. Trends Ecol Evol 25:345-353

Potts SG, Vulliamy B, Dafni A, Ne'eman G, Willmer P (2003) Linking bees and flowers: how do floral communities structure pollinator communities? Ecology 84:2628-2642

Potts SG, Vulliamy B, Roberts S, O'Toole C, Dafni A, Ne'eman G, Willmer P (2005) Role of nesting resources in organising diverse bee communities in a mediterranean landscape. Ecol Entomol 30:78-85

Pulliam HR (1988) Sources, sinks and population regulation. Am Nat 132:652-661

QGIS Development Team (2020) QGIS Geographic Information System. Open Source Geospatial Foundation Project. http://qgis.org. Accessed 20 Aug 2020

Ribeiro Jr PJ, Diggle PJ (2018) Analysis of geostatistical data. https://cran.r-project.org/web/packages/geoR/geoR.pdf. Accessed 19 Aug 2019

Roberts HP, King DI, Milam J (2017) Factors affecting bee communities in forest openings and adjacent mature forest. For Ecol Manage 394:111-122

Rubene D, Schroeder M, Ranius T (2015) Diversity patterns of wild bees and wasps in managed boreal forests: Effects of spatial structure, local habitat and surrounding landscape. Biol Conserv 184:201-208

Schindler M, Diestelhorst O, Härtel S, Saure C, Scharnowski A, Schwenninger HR (2013) Monitoring agricultural ecosystems by using wild bees as environmental indicators. BioRisk 71:53-71
Scheper J, Holzschuh A, Kuussaari M, Potts SG, Rundlöf M, Smith HG, Kleijn D (2013) Environmental factors driving the effectiveness of European agri-environmental measures in mitigating pollinator loss - a meta-analysis. Ecol Lett 16:912-920

Scheper J, Bommarco R, Holzschuh A et al (2015) Local and landscape-level floral resources explain effects of wildflower strips on wild bees across four European countries. J Appl Ecol 52:1165-1175

Steffan-Dewenter I, Tscharntke T (2001) Succession of bee communities on fallows. Ecography (Cop) 24:83-93

Steffan-Dewenter I, Münzenberg U, Bürger C, Thies C, Tscharntke T (2002) Scale-dependent effects of landscape context on three pollinator guilds. Ecology 83:1421-1432

Tscharntke T, Tylianakis JM, Rand TA et al (2012) Landscape moderation of biodiversity patterns and processes-eight hypotheses. Biol Rev 87:661-685

Wastian L, Unterweger PA, Betz O (2016) Influence of the reduction of urban lawn mowing on wild bee diversity (Hymenoptera, Apoidea). J Hymenopt Res 49:51-63

Westphal C, Steffan-Dewenter I, Tscharntke T (2003) Mass flowering crops enhance pollinator densities at a landscape scale. Ecol Lett 6:961-965

Westphal C, Bommarco R, Carré G et al (2008) Measuring bee diversity in different European habitats and biogeographical regions. Ecol Monogr 78:653-671

Westrich P (1989) Die Wildbienen Baden-Württembergs. Eugen Ulmer, Stuttgart

Westrich P (2018) Die Wildbienen Deutschlands. Eugen Ulmer, Stuttgart

Wood TJ, Holland JM, Goulson D (2017) Providing foraging resources for solitary bees on farmland: current schemes for pollinators benefit a limited suite of species. J Appl Ecol 54:323-333

Wray JC, Elle E (2014) Flowering phenology and nesting resources influence pollinator community composition in a fragmented ecosystem. Landsc Ecol 30:261-272

Wu P, Axmacher JC, Li X, Song X, Yu Z, Xu H, Tscharntke T, Westphal C, Liu Y (2019) Contrasting effects of natural shrubland and plantation forests on bee assemblages at neighboring apple orchards in Beijing, China. Biol Conserv 237:456-462

Zurbuchen A, Müller A (2012) Wildbienenschutz-von der Wissenschaft zur Praxis. Haupt, Bern

Zuur AF, Ieno EN, Smith GM (2007) Analyzing ecological data. Springer, New York

Zuur AF, Ieno EN, Walker NJ, Saveliev AA, Smith GM (2010) Mixed effects models and extensions in ecology with R. Springer, New York

Zuur AF, Ieno EN, Saveliev AA (2017) Beginner's guide to spatial, temporal, and spatial-temporal ecological data analysis with R-INLA. Highland Statistics Ltd., Newburgh

Publisher's Note Springer Nature remains neutral with regard to jurisdictional claims in published maps and institutional affiliations. 